\title{
Relation Between Absoute Nucelated Red Blood Cell Count at Birth and Retinopathy of Prematurity
}

Sung Woo Cho, M.D., Seung Hyun Lee, M.D., and Yeon Kyun Oh, M.D.

Department of Pediatrics, Wonkwang University School of Medicine, Iksan, Korea

\section{ABSTRACT}

Purpose: The aim of this study is to prove the association between potential fetal hypoxia and retinopathy of prematurity (ROP) development and absolute nucleated red blood cell (aNRBC) is used to evaluate it in premature infants without any hypoxic or ischemic history.

Methods: Medical records of 43 premature infants with ROP who were admitted to the neonatal intensive care unit at Wonkwang University Hospital from January 2004 to December 2014 were analyzed retrospectively. We excluded 15 infants who had a confounding medical condition that could have increased the aNRBC count. Finally, 28 premature infants affected by ROP were enrolled and compared with 28 pairmatched controls. The aNRBC counts at birth in these infants were compared. Statistical analysis was performed with a paired $t$-test for continuous data, and a Fisher's exact test for categorical data. $P<0.05$ was considered significant.

Results: There were no significant differences in perinatal characteristics such as gestational age (GA), birth weight (BWt), Apgar scores, premature rupture of membrane ( $>24$ hours), prenatal betamethasone, surfactant or respiratory distress syndrome between the ROP and the control infants. In addition, neither group differed in major morbidities such as patent ductus arteriosus, periventricular leukomalacia, intraventricular hemorrhage ( $\geq$ Grade 2 ), or bronchopulmonary dysplasia. Regardless of the severity of ROP, the aNRBC counts at birth in premature infants with ROP were not higher than in the control infants.

Conclusion: The aNRBC counts at birth may not be related directly to the development of ROP.

Key Words: Absolute nucleated red blood cells, Fetal hypoxia, Retinopathy of prematurity

\section{INTRODUCTION}

Retinopathy of prematurity (ROP) is a postnatal disorder of the retinal vessels that develops only in the incompletely vascularized retina of premature infants ${ }^{1)}$.

The incidence of ROP has been reported in $20.3 \%$ of infants with a birth weight of less

Copyright(c)

By Korean Society of Neonatology.

All right reserved.

This is an Open-Access article distributed under the terms of the Creative Commons Attribution Non-Commercial License (http://creativecommons.org/licenses/ by-nc/4.0), which permits unrestricted non-commercial use, distribution, and reproduction in any medium, provided the original work is properly cited. 
than $1,500 \mathrm{~g}$, and in $33.2 \%$ of infants with a birth weight of less than $1,000 \mathrm{~g}^{2)}$. The incidence of ROP among very low birth weight infants has been reported to be $36.9 \%$ in our hospital ${ }^{3)}$.

ROP progresses in two phases. The first phase begins with cessation of retinal vascular growth and vessel regression due to hyperoxia, followed by the second phase in which insufficient vascularization of the developing retina creates hypoxia and hypoxia-induced pathological retinal vessel growth ${ }^{4-7)}$. Thus, hypoxia of retinal cells from secondary and perinatal events may be one of the possible reasons for $\mathrm{ROP}^{4-7)}$.

In some reports, fetal hypoxia-ischemia induced an increased rate of ROP in conditions such as fetal growth restriction and severe neonatal asphyxia, conditions that are affected by a compromised retinal blood flow and/or oxygen supply ${ }^{6-9)}$. These conditions are also noted in maternal pregnancy-induced hypertension, pre-eclampsia, maternal diabetes mellitus, maternal smoking and $\mathrm{Rh}$ isoimmunization ${ }^{10-14)}$.

Absolute nucleated red blood cell (aNRBC) called erythroblasts or normoblasts are rarely found circulating in older children but are commonly seen in the blood of newborns, due to the fact that aNRBCs are primarily produced in the fetal bone marrow in response to erythropoietin, and stored in the bone marrow as precursors to reticulocytes and mature erythrocytes. Many acute and chronic stimuli increase the circulating aNRBC counts from an increased erythropoietic activity ${ }^{15,16)}$.

Lubetzky et al. ${ }^{17)}$ reported a case matched analysis showing that there was an elevation of aNRBC counts at birth in premature infants who later developed ROP. In this report, maternal and fetal hypoxic or ischemic conditions were excluded because they may influenced the counts of aNRBC at birth. They suggested that an increased aNRBC count at birth which is associated with relative fetal hypoxia followed by erythropoietin, and potential or long-lasting fetal hypoxia and/or ischemia may play a role in the pathogenesis of ROP.

Thus, the aim of this study is to evaluate potential relationship between fetal hypoxia and ROP development for premature infants without hypoxic or ischemic medical history, who later developed ROP, had higher aNRBC counts at birth compared with control infants.

\section{MATERIALS AND METHODS}

The medical records of 43 premature infants with ROP who were admitted to the neonatal intensive care unit at Wonkwang University Hospital from January 2004 to December 2014 were analyzed retrospectively. We included only who were gestational age (GA) $<34$ weeks and their birth weight (BWt) $<2000 \mathrm{~g}$. We excluded 15 infants with intrauterine growth retraction $(<10$ percentile in Lubechencho curves) ${ }^{18,19)}$, pregnancy induced hypertension $^{20)}$, gestational diabetes mellitus ${ }^{21)}$, placental abruption or placenta previa ${ }^{22)}$, Apgar scores $<4$ in 1 or 5 minutes, perinatal infection (eg, maternal fever and white blood cells $>15,000 / \mathrm{mm}^{3}$ ) or chorioamnionitis (eg, maternal fever, abdominal tenderness, maternal tachycardia [>100/min], fetal tachycardia [>160/min] and foul amniotic fluid ${ }^{23)}$, and blood group incompatibility with positive Coombs' test. Because these variables are known to affect neonatal aNRBC counts, we

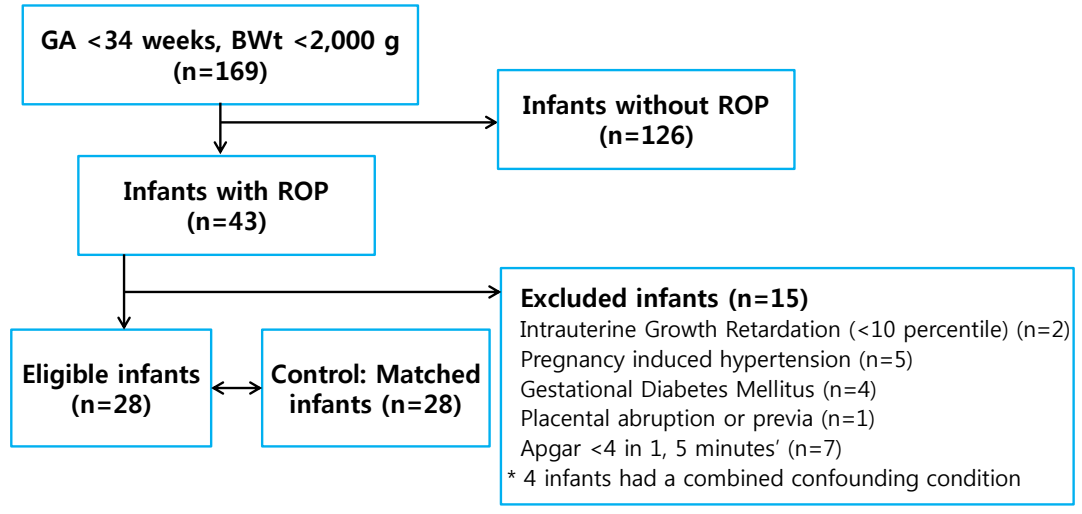

Figure 1. Study subjects. Of 43 infants with ROP, 15 infants who had a confounding condition that can increase aNRBCs, and the 4 infants who had a combined confounding condition, were excluded. Finally 28 infants with ROP and 28 matched control infants with the same gestational age (GA), birth weight (BWt), and 1, 5minute Apgar score were compared. Abbreviation: ROP, retinopathy of prematurity. 
exclude them, and only evaluate a potential aNRBC effect to development of ROP. Finally, 28 premature infants with ROP were enrolled and compared with 28 pair matched controls who had the same GA, BWt and 1, 5-minute Apgar score (Figure 1). The perinatal characteristics, major morbidities, and hematologic parameters including aNRBC counts at birth were also compared.

For ROP screening, all infants with a BWt $\leq 1,500 \mathrm{~g}$ or a GA of $\leq 32$ weeks and selected patients with a BWt of 1,500-2,000 g, who required oxygen therapy, underwent an indirect opthalmoscope 4-6 weeks after birth according to the 2006 American Academy of Pediatrics (AAP) guidelines ${ }^{24)}$.

Statistical analysis was performed with a paired $t$-test for continuous data, and a Fisher's exact test for categorical data. $P$-value $<0.05$ was considered statistically significant.

\section{RESULTS}

A total of 28 infants with ROP were compared with a matched control group. There was no significant difference between the groups with respect to perinatal characteristics according to the Apgar score, premature rupture of membrane (PROM),

Table 1. Perinatal Characteristics of Infants with Retinopathy of Prematurity and Their Matched Controls

\begin{tabular}{|c|c|c|c|}
\hline & $\begin{array}{l}\text { Infants } \\
\text { with ROP } \\
(\mathrm{n}=28)\end{array}$ & $\begin{array}{l}\text { Control } \\
(n=28)\end{array}$ & $\begin{array}{c}P- \\
\text { value }\end{array}$ \\
\hline GA (wks) (range) & $\begin{array}{l}29.1 \pm 2.0 \\
(26-33)\end{array}$ & $\begin{array}{l}28.4 \pm 1.7 \\
(25-32)\end{array}$ & 0.164 \\
\hline BWt (g) (range) & $\begin{array}{c}1,272 \pm 251 \\
(810-1,850)\end{array}$ & $\begin{array}{l}1,204 \pm 280 \\
(540-1,890)\end{array}$ & 0.339 \\
\hline \multicolumn{4}{|l|}{ Apgar } \\
\hline $1 \min$ & $4.1 \pm 1.0$ & $4.2 \pm 1.3$ & 1.000 \\
\hline $5 \min$ & $6.3 \pm 1.0$ & $6.4 \pm 1.5$ & 0.770 \\
\hline PROM ( $\geq 24$ hrs), n (\%) & $11(39.3)$ & $9(32.1)$ & 0.781 \\
\hline $\begin{array}{l}\text { Administration of betamethasone, } \\
\mathrm{n}(\%)\end{array}$ & $13(46.4)$ & $16(57.1)$ & 0.593 \\
\hline $\begin{array}{l}\text { Respiratory distress syndrome, } \mathrm{n} \\
(\%)\end{array}$ & $17(60.7)$ & $23(82.1)$ & 0.138 \\
\hline Surfactant administration, n(\%) & $12(42.9)$ & $19(67.9)$ & 0.106 \\
\hline Patent ductus arteriosus, n(\%) & $8(28.6)$ & $5(15.2)$ & 0.528 \\
\hline Ibuprofen administration, $\mathrm{n}(\%)$ & $8(28.6)$ & $5(15.2)$ & 0.528 \\
\hline
\end{tabular}

Plus-minus values are mean \pm SD.

Abbreviations: ROP, Retinopathy of prematurity; GA, gestational age; BWt, birth weight; PROM, premature rupture of membrane. prenatal administration of betamethasone, respiratory distress syndrome, surfactant administration, patent ductus arteriosus (PDA) or ibuprofen (brufen syrup ${ }^{\circledR}$ ) administration (Table 1). By design, the case and control group had a similar GA, BWt, and 1, 5-minute Apgar score.

In addition, we compared the major morbidities and oxygenation supplements of ROP infants with the matched control group. We found no significant difference in major morbidities such as periventricular leukomalacia (PVL), intraventricular hemorrhage (IVH) ( $\geq \mathrm{G} 2$ ) and bronchopulmonary dysplasia (BPD) defined as treated with more than $21 \%$ oxygen for at least 28 days postnatally between the two groups ${ }^{25)}$. And, oxygen supplementation such as the duration of ventilator therapy, duration of oxygen therapy, required maximal fraction of inspired oxygen $\left(\mathrm{FiO}_{2}\right)$, and duration of total parenteral nutrition (TPN) was also no different in both groups (Table 2).

In the 28 ROP infants, 11 infants (39.3\%) were in Stage I, 3 infants (10.7\%) were in Stage II, and 14 infants (50.0\%) were in Stage III. Regarding the severity of ROP, 17 infants (60.7\%) were graded at a more severe stage than Stage II, and 14 infants (50.0 $\%)$ at a more severe stage than Stage III. Thirteen infants (46.4\%) needed surgery.

We compared the hematologic parameters including aNRBC of ROP infants with the matched control group. There were no significant differences between the infants with ROP and the control group in terms of hematocrit, absolute lymphocyte, and platelets counts. And, to evaluate whether infants who developed ROP had higher aNRBC counts at birth compared with the control infants, we examined their aNRBC counts.

Table 2. Major Morbidities and Oxygenation Supplementation in Infants with Retinopathy of Prematurity and Their Matched Controls

\begin{tabular}{lccc}
\hline & $\begin{array}{c}\text { Infants } \\
\text { with ROP } \\
(\mathrm{n}=28)\end{array}$ & $\begin{array}{c}\text { Control } \\
(\mathrm{n}=28)\end{array}$ & $\begin{array}{c}P \text { - } \\
\text { value }\end{array}$ \\
\hline Ventilator duration (d) (n=21 vs. 23) & $8.7 \pm 10.1$ & $6.4 \pm 9.1$ & 0.427 \\
Duration of oxygen (d) & $37.8 \pm 27.5$ & $36.4 \pm 30.7$ & 0.858 \\
Maximal FiO $_{2}$ (\%) & $54.5 \pm 25.7$ & $45.4 \pm 20.7$ & 0.153 \\
Duration of TPN (day) & $20.1 \pm 11.2$ & $16.5 \pm 12.8$ & 0.268 \\
Periventricular leukomalacia, $\mathrm{n}$ & 3 & 2 & 1.000 \\
Intraventricular hemorrhage ( $\geq \mathrm{G} 2), \mathrm{n}$ & 2 & 5 & 0.422 \\
Bronchopulmonary dysplasia, $\mathrm{n}$ & 17 & 16 & 1.000 \\
\hline
\end{tabular}

Plus-minus values are mean \pm SD.

Abbreviations: ROP, retinopathy of prematurity; $\mathrm{FiO}_{2}$, fraction of inspired oxygen; TPN, total parenteral nutrition. 
Table 3. Comparison of Hematologic Findings Including between Infants with Retinopathy of Prematurity and Their Matched Controls

\begin{tabular}{lccc}
\hline & $\begin{array}{c}\text { Infants with ROP } \\
(\mathrm{n}=28)\end{array}$ & $\begin{array}{c}\text { Control } \\
(\mathrm{n}=28)\end{array}$ & $P^{*}$ \\
\hline aNRBC $\left(/ \mathrm{mm}^{3}\right)$ & & & \\
$\quad$ Total ROP $(\mathrm{n}=28)$ & $4,181 \pm 590$ & $4,244 \pm 390$ & 0.639 \\
Stage I $(\mathrm{n}=11)$ & $4,109 \pm 526$ & & 0.384 \\
$\geq$ Stage II $(\mathrm{n}=17)$ & $4,229 \pm 643$ & 0.923 \\
$\geq$ Stage III $(\mathrm{n}=14)$ & $4,323 \pm 666$ & & 0.630 \\
with operation $(\mathrm{n}=13)$ & $4,342 \pm 636$ & & 0.546 \\
Hematocrit $(\%)$ & $45.6 \pm 6.5$ & $47.9 \pm 4.4$ & 0.127 \\
Platelets $\left(10^{3} / \mu \mathrm{L}\right)$ & $235.8 \pm 76.1$ & $209.5 \pm 73.2$ & 0.193 \\
Absolute lymphocytes $\left(10^{3} / \mu \mathrm{L}\right)$ & $3.8 \pm 2.7$ & $4.0 \pm 2.4$ & 0.771 \\
\hline
\end{tabular}

Values are mean \pm SD.

Abbreviations: aNRBC, absolute nucleated red blood cell; ROP, retinopathy of prematurity.

*paired $t$-test: infants with ROP vs. control group.

There was no significant difference in the aNRBC counts of ROP infants with Stage I $(P=0.384)$, a more severe stage than Stage II $(P=0.923)$ or a more severe stage than Stage III $(P=0.630)$ compared with the control infants. Moreover, no difference was observed in aNRBC counts in infants who underwent surgery compared with the control infants $(P=0.546)$ (Table 3$)$. Regardless of the severity of ROP, the aNRBC counts at birth in premature infants with ROP were not higher than in the control infants.

\section{DISCUSSION}

ROP is a major ocular disorder developed in the incompletely vascularized retina of premature infants, and is associated with significant sequelae that result in blindness. It was described by Lutbetzky et al. ${ }^{17)}$ that when defining a subgroup of preterm infants at risk for ROP, elevated aNRBC counts at birth may help.

ANRBCs clear rapidly after birth in normal neonates, with the aNRBC count falling by approximately $50 \%$ by 12 hours of age, $20-30 / \mathrm{mm}^{3}$ by 48 hours of age, and no remaining aNRBCs after 3-4 days of life ${ }^{26-28)}$, however in premature infants, aNRBCs may persist in small numbers for up to 1 week $^{27,28)}$. The mean normal values of aNRBCs in the first few hours of life in healthy term newborn infants is approximately $500-1,000 / \mathrm{mm}^{3}$, however these values are normally up to $10,000 / \mathrm{mm}^{3}$ in small pre- mature newborns ${ }^{21,26,27,29)}$.

Increased aNRBC counts are seen in combination with longstanding erythropoietin caused by fetal hypoxia and/or ischemia, which have been found in pregnancies complicated by intrauterine growth restriction, maternal hypertension, preeclampsia, maternal smoking, Rh isoimmunization and maternal diabetes $^{10-14)}$. When adding chronic hypoxia to the above, raised aNRBCs have also been found physiologically in preterm newborns ${ }^{22,27,29)}$. In the present study, we excluded conditions known to compromise retinal blood flow and/or oxygen supply such as the above-mentioned variables because these factors are known to affect neonatal aNRBC counts.

It is not yet clearly between increased circulating neonatal aNRBC counts and ROP mechanism. However, it is accepted that relative fetal hypoxia results in increased levels of erythropoietin, which in turn leads to stimulation of erythropoiesis and increased numbers of circulating aNRBCs. Furthermore, the need for an oxygen supply, due to repeated hypoxic and hyperoxic episodes, may be an important factor in the pathogenesis of $\mathrm{ROP}^{15,18,22,30)}$. A few studies have been performed to determine the correlation between high aNRBC levels at birth and $\mathrm{ROP}^{17,31-33)}$.

Lubetzky et al. ${ }^{17)}$ found that an elevation in the aNRBC count of premature infants, relative to fetal hypoxia, developed ROP, which is supported by the fact that long-lasting fetal hypoxia and/or ischemia may act an important portion of ROP pathophysiology. In their report, the relationship between hypoxia and ROP was not explained entirely, however hypoxic condition increase vascular endothelial growth factor production, which may stimulate neovascularization secondary. Also, it is possible that hypoxic condition stimulate insulinlike growth factor binding protein-1 production which may decrease free insulin-like growth factor concentrations, prevent normal vessel growth as a result. Niranjan et al. ${ }^{31)}$ also reported that the aNRBC at birth could be considered as a screening tool because an increase in the aNRBC count correlated with fetal hypoxia. However, Gotru et al. ${ }^{32)}$ also reported the relationship between ROP and the aNRBC at birth, in which they hypothesized that infants with ROP over stage II have a higher aNRBC count at birth. They concluded that the aNRBC count at birth was not related to the development of severe ROP. Here, we also carried out a case-matched study similar to the 3 abovementioned reports, in which we could not find any relationship between the aNRBC count at birth and the development of 
ROP. Furthermore, regardless of the severity of ROP, including surgery cases, the aNRBC count at birth in premature infants with ROP was not higher than in the control infants. So, we agree with the Gotru's report that the aNRBC count at birth was not related to the development of severe ROP. However, Christensen et al. ${ }^{33)}$ reported that aNRBC count over the $95 \%$ limit at birth is related with severe ROP ( $\geq$ Stage 3 ). Moreover, Niranjan et al. ${ }^{31)}$ reported that the more severity of ROP, the higher aNRBC count significantly. Hence aNRBC count in ROP is more significant in the sensitivity, specificity, and positive predictive value than other hematological parameters. In fact, extreme increases in aNRBCs are seen physiologically in premature infants and infants with labour and vaginal birth, and may be found without asphyxia ${ }^{15)}$. Even increase of aNRBC is seen as idiopathic $^{15)}$. Thus, we cannot support the suggestion that an increased aNRBC count at birth is related to the development of ROP

Other hematologic indices as a hematocrit, absolute lymphocyte count, and platelets also known to be an indicator of fetal hypoxia. We founded these indices are not good indicator to detect the fetal hypoxia in this report, because which might indicate acute rather than chronic hypoxia. Lubetzky et al. ${ }^{17)}$ also founded that these indices are not elevated in chronic hypoxia infants.

However, to conclude that the aNRBC affect the development of ROP, more analyses are needed. That is because many infants are excluded in this study for several reasons and the sample size is too small.

We conclude that the aNRBC count at birth was not higher in premature infants who developed ROP compared with that in the control infants. Therefore aNRBC counts at birth may not be related directly to the development of ROP.

\section{ACKNOWLEDGEMENT}

This study was supported by Wonkwang University in 2015.

\section{REFERENCES}

1) Phelps DL. Retinopathy of prematurity. In:Martin RJ, Fanaroff AA, Walsh MC. Fanaroff and Martin's neonatal-perinatal medicine. 9th ed. St. Louis: Elsevier Mosby, 2011:1764-9.
2) Chiang MF, Arons RR, Flymm JT, Starren JB. Incidence of retinopathy of prematurity from 1996 to 2000. Analysis of a comprehensive New York State patient database. Ophthalmology 2004;111:1317-25.

3) Ra EY, Bang HI, Oh YK, Yang YS. Incidence, timing of screening examinations and perinatal risk factors for retinopathy of prematurity in very low birth weight infants. Korean J Perinatol 2002;13:390-8.

4) Smith LE. Pathogenesis of retinopathy of prematurity. Semin Neonatol 2003;8:469-73.

5) Chen J, Smith LE. Retinopathy of prematurity. Angiogenesis 2007;10:133-40.

6) Mccolm JR, Fleck BW. Retinopathy of prematurity: causation. Semin Neonatol 2001;6:453-60.

7) Hellstrm A, Smith LE, Dammann O. Retinopathy of prematurity. Lancet 2013;382:1445-57.

8) Bardin C, Zelcowitz P, Papageorgiou A. Outcome of small-forgestational age and appropriate-for-gestational age infants born before 27 weeks of gestation. Pediatrics 1997;100:e4.

9) Arroe M, Peitersen B. Retinopathy of prematurity in a Danish neonatal intensive care unit, 1985-1991. Acta Ophthalmol Suppl 1993;210:37-40.

10) Teramo KA, Widness JA, Clemons GK, Voutilainen P, McKinlay S, Schwartz R. Amniotic fluid erythropoietin correlates with umbilical plasma erythropoietin in normal and abnormal pregnancy. Obstet Gynecol 1987;69:710-6.

11) Mamopoulos M, Bili H, Tsantali C, Assimakopoulos E, Mantalenakis S, Farmakides G. Erythropoitin umbilical serum levels during labor in women with preeclampsia, diabetes, and preterm labor. Am J Perinatol 1994;11:427-9.

12) Salvesen DR, Brudenell JM, Snijders RJ, Ireland RM, Nicolaides KH. Fetal plasma erythropoietin in pregnancy complicated by maternal diabetes mellitus. Am J Obstet Gynecol 1993; 168:88-94.

13) Varvarigou A, Beratis NG, Makri M, Vagenakis AG. Increased levels and positive correlation between erythropoietin and hemoglobin concentration s in newborn children of mothers who smokers. J Pediatr 1994;124:480-2.

14) Voutilainen PE, Widness JA, Clemons GK, Schwartz R, Teramo KA. Amniotic fluid erythropoietin predicts fetal distress in $\mathrm{Rh}$ immunized pregnancies. Am J Obstet Gynecol 1989;160:42934.

15) Hermansen MC. Nucleated red blood cells in the fetus and newborn. Arch Dis Child Fetal Neonatal Ed 2001;84:211-5.

16) Sills RH, Hadley RA. The significance of nucleated red blood cells in the peripheral blood of children. Am J Pediatr Hematol Oncol 1983;5:173-7.

17) Lubetzky R, Stolovitz C, Dollberg S, Minouni FB, Salomon M, Mandel D. Nucleated red blood cells in preterm infants with 
retinopathy of prematurity. Pediatrics 2005;116;e619-22.

18) Minior VK, Bernstein PS, Divon MY. Nucleated red blood cells in growth-restricted fetuses: associations with short-term neonatal outcome. Fetal Diagn Ther 2000;15:165-9.

19) Lubchenco LO, Hansman C, Dressler M, Boyd E. Intrauterine growth as estimated from live-born birth weight data at 24 to 42 weeks gestation. Pediatrics 1963;32:793-9.

20) Sinha HB, Mukherjee AK, Bala D. Cord blood haemoglobin (including foetal haemoglobin), and nucleated red cells in normal and toxaemic pregnancies. Indian Pediatr 1972;9:5403.

21) Green DW, Mimouni G. Nucleated erythrocytes in healthy infants and in infants of diabetic mothers. J Pediatr 1990;166: 129-31.

22) Korst LM, Phelan JP, Ahn MO, Martin GI. Nucleated red blood cells: an update on the marker for fetal asphyxia. Am J Obstet Gynecol 1996;175:843-6.

23) Tita AT, Andrews WW. Diagnosis and management of clinical chorioamnionitis. Clin Perinatol 2010;37:339-54.

24) Section on Ophthalmology, American Academy of Pediatrics, American Academy of Ophthalmology, American Association for Pediatric Ophthalmology and Strabismus. Screening examination of premature infants for retinopathy of prematurity. Pediatrics 2006;117:572-6.

25) Kinsella JP, Greenough A, Abman SH. Bronchopulmonary dysplasia. Lancet 2006;367:1421-31.
26) Naeye RL, Localio AR. Determinig the time before birth when ischemia and hypoxemia initiated cerebral palsy. Obstet Gynecol 1995;86:713-9.

27) Green DW, Hendon B, Mimouni FB. Nucleated erythrocytes and intraventricular hemorrhage in preterm neonates. Pediatrics 1995;96:475-8.

28) Oski FA, Naiman JL. Normal blood values in the newborn period. Hematologic problems in the newborn. 2nd ed. WB Saunders, Philadelphia; 1972:1-30.

29) Buonocore G, Perrone S, Gioia D, Gatti MG, Massafra C, Agosta $R$, et al. Nucleated red blood cell countat birth as an index of perinatal brain damage. Am J Obstet Gynecol 1999;181: 1500-5.

30) Vatansever U, Acunas B, Demir M, Karasalihoglu S, Ekuklu G, Ener S, et al. Nucleated blood cell counts and erythropoietin levels in high-risk neonates. Pediatr Int 2002;44:590-5.

31) Niranjan HS, Reddy BK, Benakappa N, Murthy K, Shivananda $\mathrm{S}$, Veeranna $\mathrm{V}$. Role of hematological parameters in predicting retinopathy of prematurity (ROP) in preterm neonates. Indian J Pediatr 2013;80:726-30.

32) Gotru S, Ahlers-Schmidt CR, Delmore P, Shaw J, Bloom BT. The absolute nucleated red blood cell (aNRBC) count at birth is not an indicator for retinopathy of prematurity (ROP). J Perinatol 2013;33:21-4.

33) Christensen RD, Henry E, Andres RL, Bennett ST. Reference ranges for blood concentrations of nucleated red blood cells in neonates. Neonatology 2011;99:289-94. 